of particular interest. The book is well illustrated with many photographs, maps, and tables that provide background material useful for anyone concerned with the history of aircraft weather reconnaissance. It compares with the extensive descriptions of United States reconnaissance activities contained in the AMS's publication Thor's Legions, by John F. Fuller.

Techniques employed in the determination of wind included triple-drift measurements and sometimes the

\section{The Last of the Crickets}

From late summer till midautumn the cheerful chirps of crickets have marked our moderate and warm evenings and nights. Now, with chilly nights prevailing, the cricket chorus is heard less often, and soon will

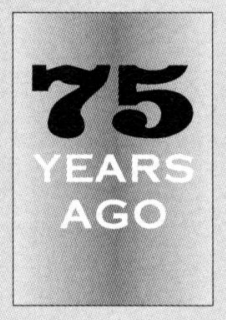
be stilled. A temperature of 50 degrees Fahrenheit is about the cold limit for the chirping of the most regular and musical of our crickets. A high chirper, however, was heard at a temperature as low as 40 .

On the warmest evening when observations were made, the crickets were chirping about as fast as the chirps could be counted, 183 per minute at a temperature of 79 . Another time the rate was 165 per minute at 78 degrees. As the temperature falls the rate regularly declines, till at 52 , the lowest temperature at which chirps were counted, the rate was twice found to be 56 per minute, or less than a third as fast as on the warmest nights. .

$[\ldots]$ In case you wish to use the cricket for a convenient thermometer, it is only necessary to remember a simple rule. Count the number of chirps in 14 seconds, add 40, and you'll have the temperature. On this basis, the temperature is obtained within one degree at least three times our of four, and within two degrees nine times out of ten.-C. F. Brooks in "Why the Weather" (Science Service).

Bull. Amer. Meteor. Soc., 7, 142. use of the thermal wind equation. The frequent estimation of sea level pressure was especially dangerous in stormy weather over the ocean when pilots had to fly just above wave tops. Observations were made from sea level to 40,000 feet, depending on the type of aircraft in use.

Many of the wartime missions were conducted in bad weather, but even in good weather reconnaissance aircrews faced the hazard of aircraft mechanical failure with subsequent ditchings and the constant threat of enemy action. Although not all meteorological flights were armed for offensive action, some did spot and attack submarines and engage in aerial combat. Many difficult landings in bad terminal weather are described and maneuvers such as those required while skimming the waves to make sea level pressure measurements indicate the skills required of the pilots.

Chapter 4, "Aircraft Experiences," is the longest chapter in the book and contains very interesting information about the procedures and operations of the weather reconnaissance flights. References are made to notable encounters and hazards such as jet streams, turbulence, icing, crashes, enemy aircraft, and u-boats. Based on extracts from aircrew accounts, log books, and diaries, the narrations provide identification of equipment, aircrew, time, and date information. The maps in Appendix 1 show the various routes associated with other military events. Many excellent photographs of equipment and personnel accompany the accounts and will be recognized by veterans of European conflict.

The mission by a four-engine Halifax bomber (Squadron 517), which took off just after midnight on D-day, 6 June 1944 on recon track Epicure, is typical of the "experiences" in this chapter. About 800 miles southwest of its base in the United Kingdom (Brawdy) it was forced to ditch because of engine failure. In darkness the eight-man crew managed to escape the sinking aircraft and transfer to its rescue dinghy. They were spotted the next day by an aircraft from a meteorological squadron based at Gibraltar and finally rescued by an American destroyer on 8 June and transferred to the USS Bogue, an aircraft carrier. After several weeks, the carrier returned to its base in Norfolk, Virginia. From Norfolk the crew was transferred to Montreal and later to England where they were given survivor leave and returned to Brawdy. The crew of a weather mission out of the United Kingdom, which took off on D-day, finally got back to its home basethree months later.

Even with satellites and advanced radar systems 